\title{
Development of High Temperature Oxidation Resistant Titanium Alloy Arconic-THOR ${ }^{\text {TM }}$
}

\author{
Fusheng Sun $^{\mathrm{a}, *}$, Ernie Crist ${ }^{\mathrm{a}}$ \\ ${ }^{\mathrm{a}}$ Arconic Engineered Structures, Inc, Niles, Ohio, USA \\ * Fusheng.sun@arconic.com
}

\begin{abstract}
$\underline{\text { Abstract }}$
The aeroengine and airframe applications of titanium alloys are often limited by their insufficient oxidation resistance to the aggressive environment at higher temperatures. A high temperature oxidation resistant titanium alloy (Arconic-THOR ${ }^{\mathrm{TM}}$ ) has been developed. This alloy is an alpha-beta alloy with superior oxidation resistance and improved creep resistance. The oxidation weight gain of Arconic-THOR ${ }^{\mathrm{TM}}$ is much lower than Ti-6242 and Beta $21 \mathrm{~s}$ in the temperature range up to $750^{\circ} \mathrm{C}$. The room and elevated temperature properties of Arconic-THOR ${ }^{\mathrm{TM}}$ are comparable to those for Ti-6242. Arconic-THOR ${ }^{\mathrm{TM}}$ also shows superior, post-thermal-exposure tensile strength, ductility, and fatigue properties, and is capable of being cold formed, hot formed, and superplastic formed, welded and heat treated to different product geometries. The microstructures and mechanical properties for sheet manufactured from the production ingots are presented and discussed in this study.
\end{abstract}

\section{$\underline{\text { Introduction }}$}

Titanium alloys are widely used as aeroengine and airframe structural components, due to their low density, good corrosion behavior, and excellent mechanical properties. However, demands for higher performance and fuel efficiency are leading to the development of aero-engine and airframe components that must operate at increased temperatures and decreased weight compared to legacy alloys. These higher performance targets have led to a continuing need for titanium alloys with excellent oxidation resistance and high strength at elevated temperatures up to $750^{\circ} \mathrm{C}$. To date, legacy airframe and engine applications requiring oxidation resistance, heat resistance and light-weight have used titanium alloys such as Ti-6Al-2Sn-4Zr-2Mo-0.1Si (Ti-6242) and Ti-15Mo-3Al-3Nb-0.2Si (Beta 21s) [1-4]; however, the maximum operating temperature of these above titanium alloys is usually limited to below $600^{\circ} \mathrm{C}$. Thermal-exposure at $650-750^{\circ} \mathrm{C}$ for prolonged periods leads to severe flaking of the Ti-6242 and Beta21s alloy [5-6]. Moreover, the Beta 21s alloy has significantly lower strength when service temperatures reach $650-750^{\circ} \mathrm{C}$ as the exposure temperatures were well above the optimum aging temperature for this alloy. Titanium alloys are being considered for use in hotter 
sections of the engine nacelles and for use in airframe structures withstanding higher operating temperatures, such as aft pylon components. These increased performance demands are linked to the hotter exhaust gases from the GE LEAP and PWA Geared Turbofan engines.

There is a need to produce titanium alloys with excellent oxidation resistance at a higher service temperature up to $750^{\circ} \mathrm{C}$. One primary object of the present study is to develop a titanium alloy (Arconic-THOR ${ }^{\mathrm{TM}}$ ) that achieves a good combination of excellent oxidation resistance, good creep resistance, tensile strength, and good post-thermal-exposure stability at elevated temperatures up to $750^{\circ} \mathrm{C}$. In addition, the titanium alloy also has good cold/hot forming ability, good superplastic forming performance, and good weldability. In this presentation, we have studied the oxidation resistance property of Arconic-THOR ${ }^{\mathrm{TM}}$, Ti6242, and beta $21 \mathrm{~s}$ in a temperature range from 650 to $750^{\circ} \mathrm{C}$. The mechanical properties such as tensile properties at room and elevated temperatures, and high cycle fatigue properties of the Arconic-THOR ${ }^{\mathrm{TM}}$ production ingot also discussed in this study.

\section{Materials and Experiments}

The Arconic-THOR ${ }^{\mathrm{TM}}$ ingot (nominal composition of Ti-6Al-4Sn-3Nb-0.5Mo-0.3Si) with a diameter of $770 \mathrm{~mm}$, and total weight of $2200 \mathrm{~kg}$ was prepared by the double vacuum arc re-melting technique. The ingot was subjected to a sequence of beta forging, alpha+beta forging and rolling down to 1,2 , and $4 \mathrm{~mm}$ thick sheets, followed by annealing.

Oxidation samples of Arconic-THOR ${ }^{\mathrm{TM}}$, Ti6242, and Beta21s were machined to a width of $20 \mathrm{~mm}$ and a length of $50 \mathrm{~mm}$. Sample surfaces were ground to a uniform finish using silicon carbide paper through 1200 grit. Samples were first detergent cleaned, then ultrasonically cleaned in acetone and ethyl alcohol, and finally air dried. The dimensions of finished samples were measured to the nearest $0.01 \mathrm{~mm}$. Oxidation tests were conducted in ceramic boats placed in a box furnace at 650,700 to $750^{\circ} \mathrm{C}$ for times up to $208 \mathrm{hr}$. The sample weight change was recorded periodically during exposure time at $0,24,48,72,96,160$, and 208 hours using a Mettler AE 160 microbalance with an accuracy of $0.01 \mathrm{mg}$. Oxidation samples were examined upon completion of thermal exposure using a Zeiss EVO MA25 scanning electron microscope (SEM), equipped with energy dispersive X-ray spectroscopy (EDS) to characterize and identify oxide phases and morphology.

Mechanical properties of the Arconic-THOR ${ }^{\mathrm{TM}}$ sheets $(1$ and $2 \mathrm{~mm}$ thick) were evaluated using room and elevated-temperature tensile testing. Flat, dog-bone specimens with a gauge dimension of $12.70 \mathrm{mmx} 50.80 \mathrm{~mm}$ or $8.90 \mathrm{~mm} \times 35.60 \mathrm{~mm}$ were prepared in either longitudinal or transverse direction of the sheets. Double hole fatigue specimens were cut from the $2 \mathrm{~mm}$ thick sheets in the longitudinal direction according to ASTM standard E466. Eight fatigue specimens were tested in the as the received condition (no thermal exposure), while an additional eight specimens were thermal-exposed at $700^{\circ} \mathrm{C}$ for $100 \mathrm{hr}$, then subjected to fatigue testing. The high cycle fatigue testing 
was performed at room temperature using the stress ratio $\mathrm{R}=0.06$, frequency of $30 \mathrm{~Hz}$, and a sine wave form.

\section{$\underline{\text { Results and Discussion }}$}

\section{Oxidation Resistance}

Figure 1 shows the results for the oxidation exposures of the Arconic-THOR ${ }^{\mathrm{TM}}$, Ti6242, and Beta21s over the temperature range of 650 to $750^{\circ} \mathrm{C}$. Total weight gain for each specimen was obtained by comparing initial and final specimen weights. Analysis of weight gain data at $650^{\circ} \mathrm{C}$ (Figure 1a) showed that the weight gain increased parabolically with respect to the time of exposure for the three alloys. The weight gain for Arconic-THOR ${ }^{\mathrm{TM}}$ after 208 hours of oxidation at $650^{\circ} \mathrm{C}$ is two and three times lower than those for Ti6242 and Beta21s, respectively. After exposure to $700^{\circ} \mathrm{C}$ for 208 hours (Figure 1b), the weight gain of Beta21s is nearly a linear function of the exposure time. The weight gain of Beta21s and Ti6242 is five and two times higher, respectively than that for Arconic-THOR ${ }^{\mathrm{TM}}$ after 208 hours of oxidation at $700^{\circ} \mathrm{C}$. Further increasing the oxidation temperature up to $750^{\circ} \mathrm{C}$ (Figure 1c), the weight gain of Beta21s is fifty times higher than that for Arconic$\mathrm{THOR}^{\mathrm{TM}}$, while the weight gain of Ti6242s is three times higher than the value for Arconic$\mathrm{THOR}^{\mathrm{TM}}$. In the temperature range from 650 to $750^{\circ} \mathrm{C}$, Arconic- THOR ${ }^{\mathrm{TM}}$ shows the best oxidation resistance compared to Ti6242s and Beta21s.

Figure 2a-2c represent SEM micrographs of the specimen surfaces for Arconic-THOR ${ }^{\mathrm{TM}}$, Ti6242, and Beta21s after exposure for 208 hours at $750^{\circ} \mathrm{C}$. The surface of Arconic-THOR ${ }^{\mathrm{TM}}$ consists of continuous, compact (void-free) oxidation layer (Figure 2a); while the surface of Ti6242 consists of discontinuous loose (void) oxidation layer with severe flaking (Figure 2b). Examination of the surface of Beta21s (Figure 2c) showed the presence of mixture of bubbles and flaking on the oxidation layer. This indicated that the Ti6242, and Beta21s lose their protective oxidation layer once exposure temperature increases up to $750^{\circ} \mathrm{C}$. Preliminary analysis of oxidation products of Arconic-THOR ${ }^{\mathrm{TM}}$ using SEM/EDS suggests that oxides is a mixture of $\mathrm{TiO}_{2}$ and $\mathrm{Al}_{2} \mathrm{O}_{3}$ with a $\mathrm{Sn}$ rich layer. Detailed examination of the oxidation resistance mechanism is being performed. 

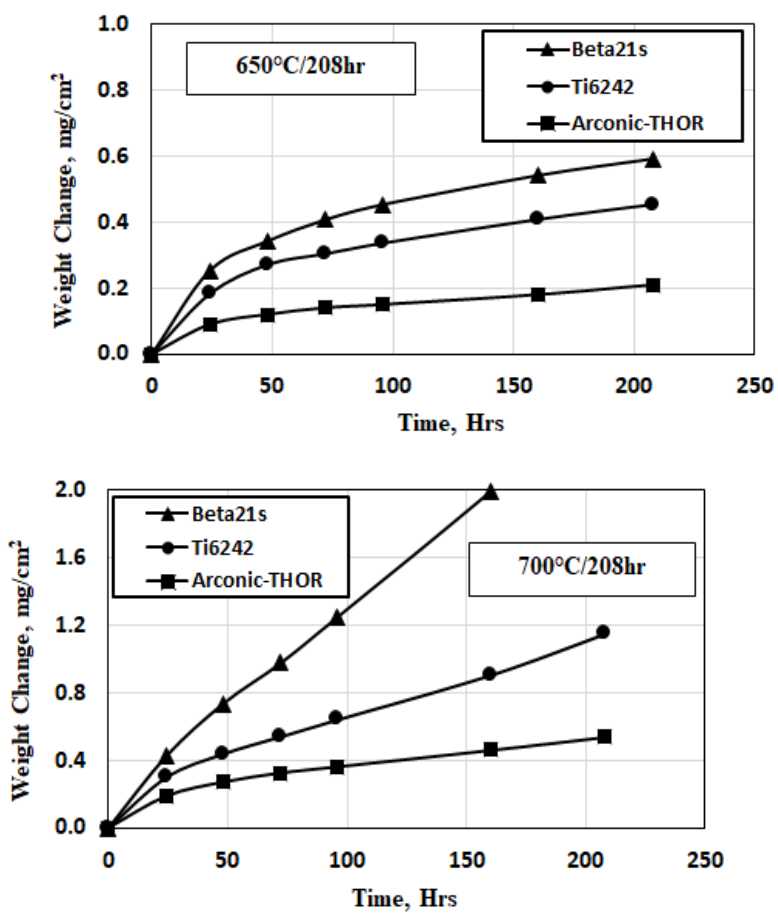
(a) $650^{\circ} \mathrm{C}$
(b) $700^{\circ} \mathrm{C}$

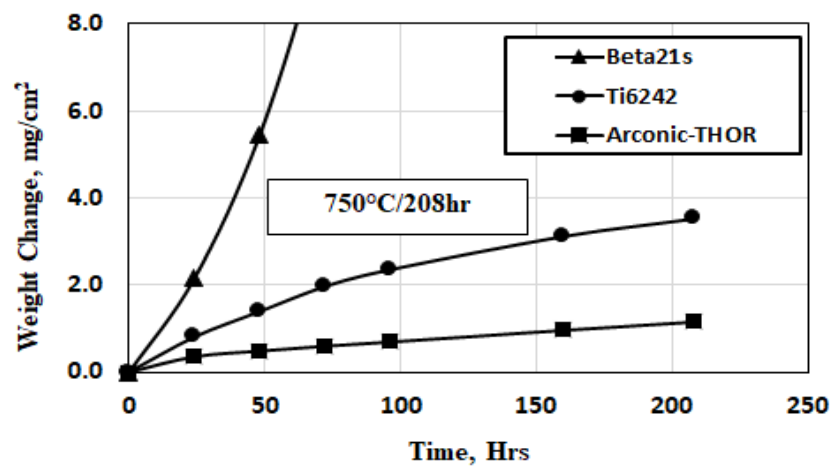

(c) $750^{\circ} \mathrm{C}$

Figure 1 Oxidation weight gain of Arconic-THOR ${ }^{\mathrm{TM}}$, Ti6242, and Beta21s at 650, 700, and $\mathbf{7 5 0}^{\circ} \mathrm{C}$. 


\section{Microstructures}

Figure 3 shows the microstructures in both the longitudinal direction and transverse directions for Arconic-THOR ${ }^{\mathrm{TM}}$ sheets with a thickness of 1 and $2 \mathrm{~mm}$. The sheets were alpha+beta hot-rolled and annealed. Cross-rolling was performed to control the crystallographic texture of the sheets and minimize anisotropy. The microstructure was composed of equiaxed grains, with an average primary alpha grain size of about 8-12 $\mu \mathrm{m}$. Uniform microstructure was observed in both the longitudinal direction and transverse direction of the $1 \mathrm{~mm}$ and $2 \mathrm{~mm}$ thick production sheets.

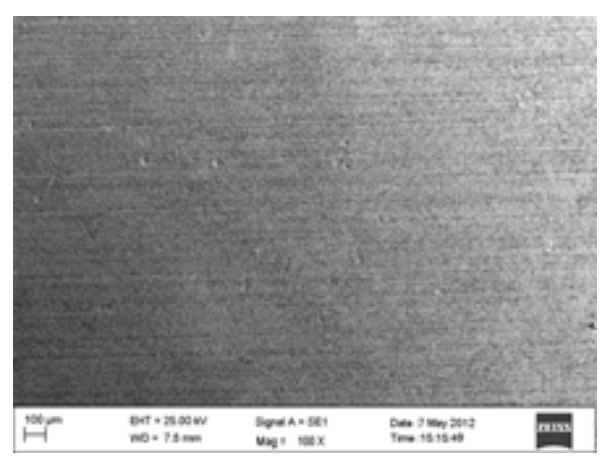

(a) Arconic-THOR ${ }^{\mathrm{TM}}$

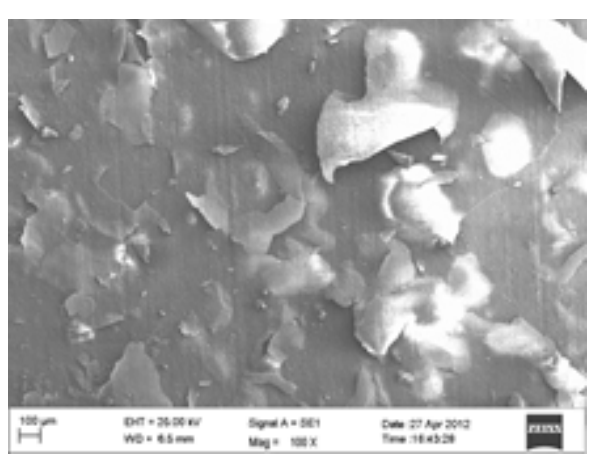

(b) Ti6242

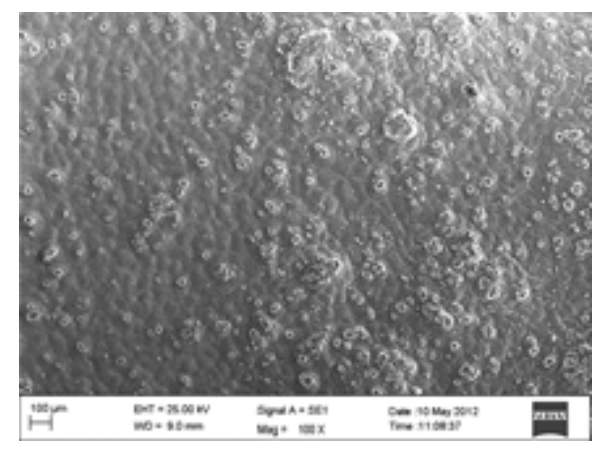

(c) Beta21s

Figure 2 SEM Micrographs of oxidation surface of Arconic-THOR ${ }^{\mathrm{TM}}$, Ti6242, and Beta21s exposed at $750^{\circ} \mathrm{C}$ for 208 hours. 


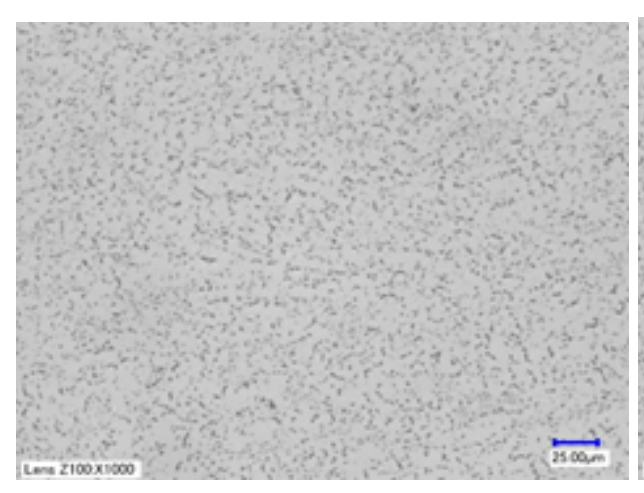

(a) $1 \mathrm{~mm}$ thick, longitudinal direction

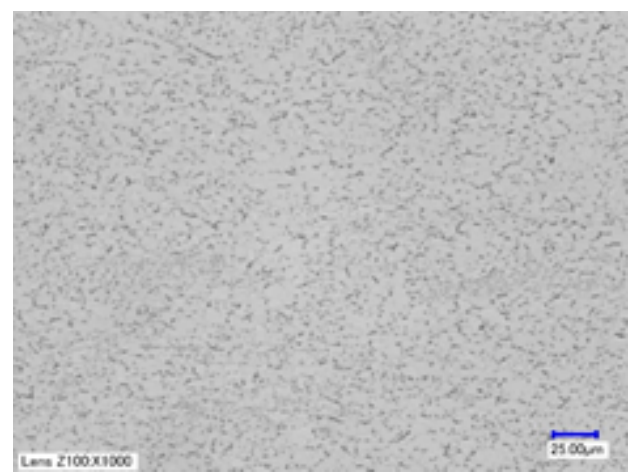

(c) $2 \mathrm{~mm}$ thick, longitudinal direction

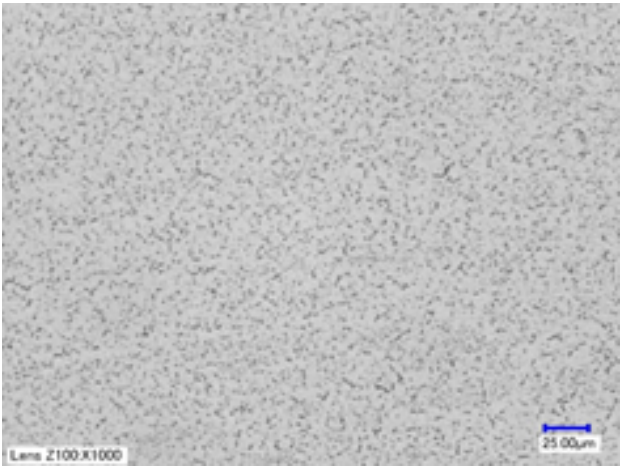

(b) $1 \mathrm{~mm}$ thick, transverse direction

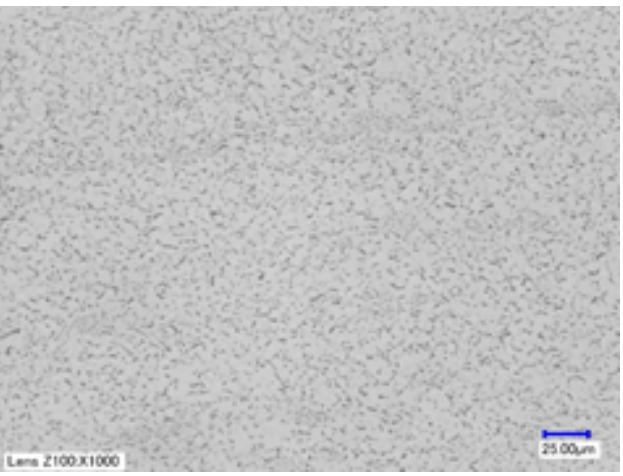

(d) $2 \mathrm{~mm}$ thick, transverse direction

Figure 3 The microstructures of Arconic-THOR ${ }^{\mathrm{TM}}$ sheets in the longitudinal and transverse direction.

\section{Tensile properties}

Figure 4a shows the tensile properties of $1 \mathrm{~mm}$ thick specimens in the longitudinal direction at different temperatures $\left(25,300,500,600,650,700\right.$, and $\left.750^{\circ} \mathrm{C}\right)$. The average yield strength (YS) and ultimate tensile strength (UTS) at room temperature are 988.7 and $1063.8 \mathrm{MPa}$, respectively. The tensile strength gradually decreases with increasing temperature, while the ductility changes slightly at first with increasing temperature to $500^{\circ} \mathrm{C}$, but increases significantly up to $750^{\circ} \mathrm{C}$. The YS and UTS in the longitudinal direction at $650^{\circ} \mathrm{C}$ are 325.4 and $447.1 \mathrm{MPa}$, respectively. The tensile properties of $1 \mathrm{~mm}$ thick specimens in the transverse direction, as a function of temperature are shown in Figure $4 \mathrm{~b}$. The average YS and UTS in the transverse direction at room temperature are 960.5 and $1014.6 \mathrm{MPa}$, 
respectively, resembling those in the longitudinal direction. These results indicate that the cross hot rolling of the sheets minimized the texture and anisotropy on tensile properties. The YS and UTS in the transverse direction at $650^{\circ} \mathrm{C}$ are 322.7 and $434.8 \mathrm{MPa}$, respectively, very close to those in longitudinal direction.

The tensile properties in both the longitudinal and transverse direction for Arconic-THOR ${ }^{\mathrm{TM}}$ $2 \mathrm{~mm}$ thick sheets are shown in Figure $4 \mathrm{c}$ and $4 \mathrm{~d}$, respectively. The results clearly indicate that the tensile strength and ductility at room temperature are not significantly affected by sheet thickness. The YS and UTS in the longitudinal direction at room temperature are 998.0 and $1076.6 \mathrm{MPa}$, while the YS and UTS in the transverse direction at room temperature is 953.2 and $997.0 \mathrm{MPa}$, respectively. Increasing the testing temperature leads to a decrease of the yield strength and ultimate tensile strength, as well as an increase of ductility up to $750^{\circ} \mathrm{C}$. The effect of temperature on the tensile property obtained for the $2 \mathrm{~mm}$ thick sheets are comparable to results obtained for the $1 \mathrm{~mm}$ thick sheets.
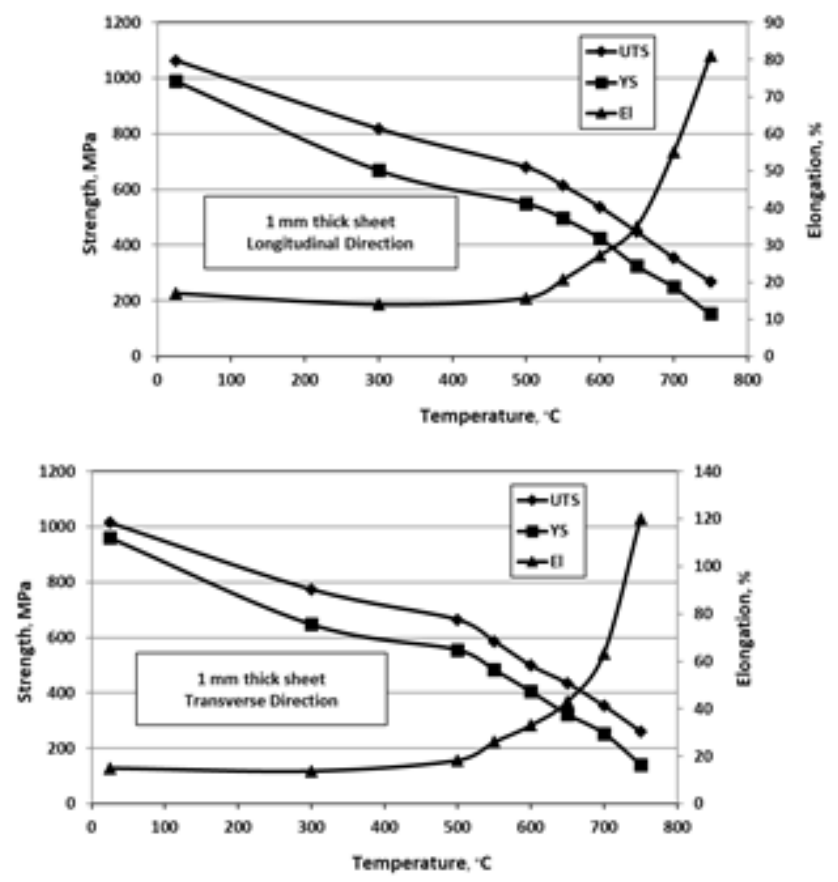

(a) $1 \mathrm{~mm}$ thick, longitudinal direction

(b) $1 \mathrm{~mm}$ thick, transverse direction 

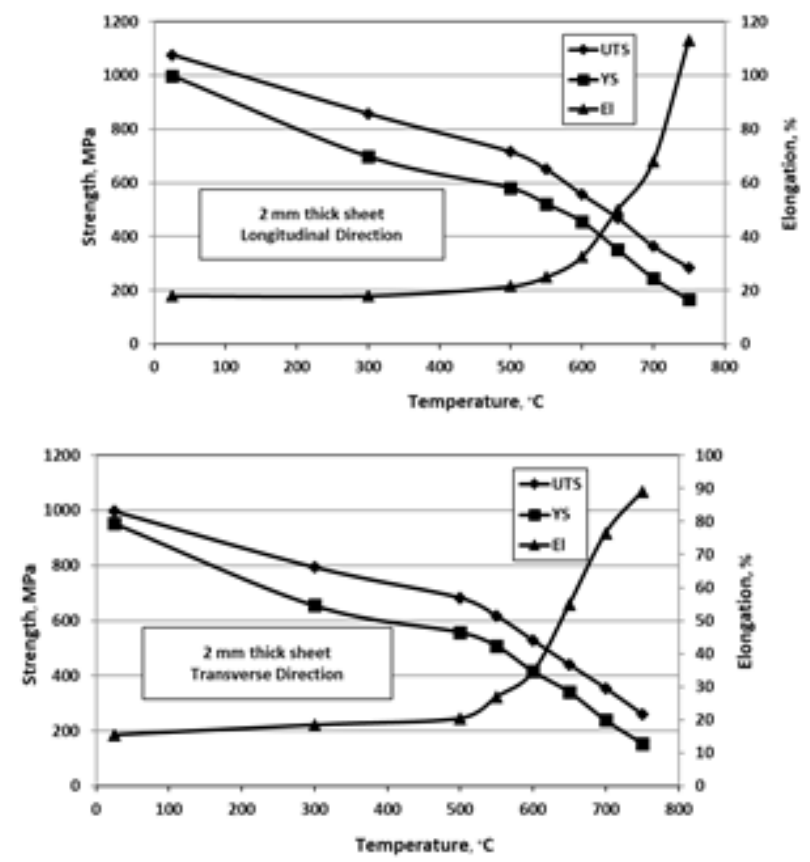

(c) $2 \mathrm{~mm}$ thick, longitudinal direction

(d) $2 \mathrm{~mm}$ thick, transverse direction

Figure 4 Tensile property of Arconic-THOR ${ }^{\mathrm{TM}}$ sheets in the longitudinal and transverse direction.

\section{High Cycle Fatigue Property}

High cycle fatigue property was performed on the $2 \mathrm{~mm}$ thick specimens in the longitudinal direction at room temperature. The double hole fatigue specimens have a size of $2 \mathrm{~mm}$ thick x 25.4 $\mathrm{mm}$ width $\mathrm{x} 210 \mathrm{~mm}$ length, with double holes of a diameter $4.76 \mathrm{~mm}$. The high cycle fatigue testing was performed using the stress ratio $\mathrm{R}=0.06$, frequency $30 \mathrm{~Hz}$, and a sine wave. The fatigue $\mathrm{S}-\mathrm{N}$ curve and fatigue limit of the Arconic-THOR ${ }^{\mathrm{TM}} 2 \mathrm{~mm}$ thick sheet in the longitudinal direction are given in Figure 5a. It can be seen that the high cycle fatigue cycles decease with increasing the maximum stress. The fatigue limit of the $2 \mathrm{~mm}$ thick sheet as received condition is $251 \mathrm{MPa}$.

To investigate the effect of oxidation layer on high cycle fatigue property of the Arconic$\mathrm{THOR}^{\mathrm{TM}}$ sheet, eight double hole fatigue specimens were thermal exposed for 100 hours at $700^{\circ} \mathrm{C}$ after machining. The fatigue testing of the eight specimens is performed at room temperature using the same fatigue testing parameters. Figure $5 \mathrm{~b}$ shows the fatigue S-N curve of the eight specimens after 
the thermal exposure. Similarly, with increasing the maximum stress, the fatigue cycles decease. The fatigue limit of the $2 \mathrm{~mm}$ thick sheet after thermal exposure is $185 \mathrm{MPa}$. It is lower than the fatigue limit of the as-received condition, but it is higher than the fatigue limit of Ti6242 under the same thermal exposure and fatigue testing condition [5,6], with a fatigue limit of $158 \mathrm{MPa}$. The improved high cycle fatigue property of Arconic-THOR ${ }^{\mathrm{TM}}$ sheet after thermal exposure is attributed to the improved oxidation resistance of Arconic-THOR ${ }^{\mathrm{TM}}$. Detailed study showed that all the fatigue cracks were initiated at the surface of the fatigue specimens, where the alpha case was generated at $700^{\circ} \mathrm{C}$ for 100 hours. The fatigue specimens of Arconic-THOR ${ }^{\mathrm{TM}}$ have three times reduction of the alpha case (7.26 $\mu \mathrm{m}$ thick) compared to that of Ti6242 (alpha case $21.07 \mu \mathrm{m}$ thick), as we observed in our previous study $[5,6]$.
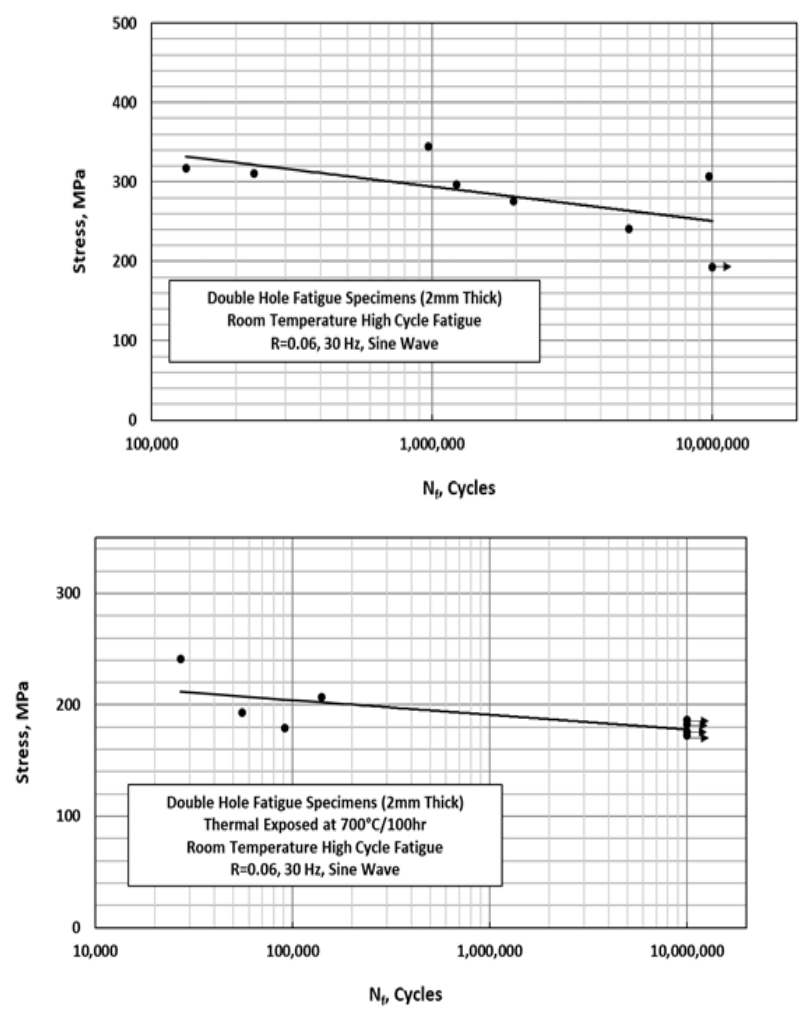

(a) As received condition

(b) Exposed for 100 hours at $700^{\circ} \mathrm{C}$

Figure 5 High cycle fatigue S-N curves for Arconic-THOR ${ }^{\mathrm{TM}} 2 \mathrm{~mm}$ thick sheets in the longitudinal direction 
(a) As received condition, (b) After exposed for 100 hours at $700^{\circ} \mathrm{C}$

\section{Conclusions}

(1) A high temperature oxidation resistant titanium alloy (Arconic-THOR ${ }^{\mathrm{TM}}$ ) has been developed, which is an alpha-beta alloy with a good combination of superior oxidation resistance and mechanical properties.

(2) In the temperature range of up to $750^{\circ} \mathrm{C}$, Arconic- THOR ${ }^{\mathrm{TM}}$ shows the best oxidation resistance compared to Ti6242s and Beta21s. The weight gain for Arconic-THOR ${ }^{\mathrm{TM}}$ after 208 hours of oxidation at $650^{\circ} \mathrm{C}$ is two and three times lower than those for Ti6242 and Beta21s, respectively. After 208 hours of oxidation at $750^{\circ} \mathrm{C}$, Arconic-THOR ${ }^{\mathrm{TM}}$ shows a continuous, protective oxidation layer, while Ti-6242, and Beta21s exhibit oxidation products described as discontinuous, blistering and severe flaking.

(3) Arconic- THOR ${ }^{\mathrm{TM}}$ sheet exhibits good tensile strength and ductility in both the longitudinal and transverse directions at room and elevated temperatures. Its tensile properties are like those of Ti6242 alloy.

(4) Arconic- THOR ${ }^{\mathrm{TM}}$ shows good high-cycle fatigue behavior at room temperature, with a fatigue limit of $251 \mathrm{MPa}$ in the as-received condition. After thermal exposure for 100 hours at $700^{\circ} \mathrm{C}$, Arconic- THOR ${ }^{\mathrm{TM}}$ has a fatigue limit of $185 \mathrm{MPa}$ at room temperature, exceeding the fatigue limit of $158 \mathrm{MPa}$ of the Ti6242 tested under the same conditions. The improved high cycle fatigue property of Arconic-THOR ${ }^{\mathrm{TM}}$ sheet after thermal exposure is attributed to its improved oxidation resistance.

\section{$\underline{\text { References }}$}

[1] P. Kofstad, P. B. Anderson, O. J. Krudtaa, J. Less-Common Metals. 3(1961) 89-97.

[2] J. Unnam, R. N. Shenoy, R. K. Clark, Oxidation of Metals. 26(1986) 231-252.

[3] J. Stringer, Acta Metalurgica. 8(1960) 758-766.

[4] T. A. Wallzce, R. K. Clark, K. E. Wiedemann, NASA Technical Memorandum. 104217(1992) 110.

[5] F. Sun, E. M. Crist, K. O. Yu, US Patent No. 9957836 B2. (2018) 1-20. 
[6] F. Sun, Arconic Engineered Structures Inc. Internal Technical Report. (2017) 1-18. 